\title{
Changes in use of cervical spine magnetic resonance imaging for pediatric patients with nonaccidental trauma
}

\author{
Ahyuda Oh, DDS, MBA, DrPH, ${ }^{1}$ Michael Sawvel, DO, ${ }^{3}$ David Heaner, BS, ${ }^{3}$ Amina Bhatia, MD, MS,, 45 \\ Andrew Reisner, MD, ${ }^{2,3}$ R. Shane Tubbs, PhD, PA-C, ${ }^{6}$ and Joshua J. Chern, MD, PhD ${ }^{2,3}$

\begin{abstract}
Departments of ${ }^{1}$ Pediatrics and ${ }^{2}$ Neurosurgery, Emory University School of Medicine; ${ }^{3}$ Pediatric Neurosurgery Associates, Children's Healthcare of Atlanta; ${ }^{4}$ Pediatric Surgery, Emory University, Atlanta; and ${ }^{5}$ Children's Physician Group, Pediatric Surgery, Children's Healthcare of Atlanta, Georgia; and ${ }^{6}$ Department of Neurosurgery, University of Alabama Birmingham School of Medicine, Birmingham, Alabama
\end{abstract}

OBJECTIVE Past studies have suggested correlations between abusive head trauma and concurrent cervical spine (c-spine) injury. Accordingly, c-spine MRI (cMRI) has been increasingly used in radiographic assessments. This study aimed to determine trends in cMRI use and treatment, and outcomes related to c-spine injury in children with nonaccidental trauma (NAT).

METHODS A total of 503 patients with NAT who were treated between 2009 and 2014 at a single pediatric health care system were identified from a prospectively maintained database. Additional data on selected clinical events were retrospectively collected from electronic medical records. In 2012, a clinical pathway on cMRI usage for patients with NAT was implemented. The present study compared cMRI use and clinical outcomes between the prepathway (2009-2011) and postpathway (2012-2014) periods.

RESULTS There were 249 patients in the prepathway and 254 in the postpathway groups. Incidences of cranial injury and Injury Severity Scores were not significantly different between the 2 groups. More patients underwent cMRI in the years after clinical pathway implementation than before $(2.8 \%$ vs $33.1 \%, p<0.0001)$. There was also a significant increase in cervical collar usage from $16.5 \%$ to $27.6 \%(p=0.004)$, and more patients were discharged home with cervical collar immobilization. Surgical stabilization occurred in a single case in the postpathway group.

CONCLUSIONS Heightened awareness of potential c-spine injury in this population increased the use of cMRI and cervical collar immobilization over a 6 -year period. However, severe c-spine injury remains rare, and increased use of cMRI might not affect outcomes markedly.

https://thejns.org/doi/abs/10.3171/2017.2.PEDS16644

KEY WORDS cervical spine injury; cervical spine MRI; child abuse; nonaccidental trauma

$\mathrm{N}$ ONACCIDENTAL trauma (NAT), or child abuse, is a significant cause of traumatic brain injury and fatality among children, especially infants and toddlers. ${ }^{2,8,25}$ Among the children who died of maltreatment in $2013,47 \%$ had suffered physical abuse,$^{33}$ and most of these cases involved intracranial injuries., ${ }^{90,13,17,27}$ Multiple studies have been published investigating the correlations between head trauma and cervical spine (c-spine) injury in these children, and the appropriate diagnostic modalities for detecting these injuries. Although the overall incidence appeared to be low, ${ }^{22}$ several studies have shown that cspine injuries are closely associated with abusive head trauma, ${ }^{4,5,15,19,21-23}$ and suggest that all children with suspected NAT should undergo c-spine MRI (cMRI) during the early stage of clinical assessment. Correspondingly, the American College of Radiology recommended that cMRI scans be considered for children with suspected NAT. ${ }^{31}$

The purpose of this study was to document changes in the usage and clinical yield of cMRI before and after the implementation of a clinical pathway on imaging studies

ABBREVIATIONS c-spine = cervical spine; $c M R I=c$-spine MRI; IQR = interquartile range; ISS = Injury Severity Score; NAT = nonaccidental trauma; $S D H=$ subdural hematoma.

ACCOMPANYING EDITORIAL See pp 269-270. DOI: 10.3171/2017.3.PEDS1775.

SUBMITTED November 21, 2016. ACCEPTED February 9, 2017.

INCLUDE WHEN CITING Published online June 30, 2017; DOI: 10.3171/2017.2.PEDS16644. 
for patients with NAT at a single pediatric health care system in the US. We began by describing the demographic and clinical characteristics of children with NAT from 2009 through 2014. We then examined whether the changes in selected clinical events and outcomes before and after clinical pathway implementation were significant. The main events of interest were cMRI use, cervical collar use, cranial and c-spine injury diagnoses, and surgical stabilization of the cervical spine.

\section{Methods}

\section{Patients and Settings}

The Trauma Registry at Children's Healthcare of Atlanta (CHOA) is a prospectively collected and state-mandated database with the requisite data fields. The mechanism of trauma is subcategorized into accidental, nonaccidental, or undetermined by a physician team dedicated exclusively to child protection. Entry into the database was made within 2 weeks of the patient's visit to the hospital system. Query of the database revealed a total of 503 children younger than 9 years of age whose injuries were categorized as NAT between January 2009 and December 2014. This study was approved by the CHOA Institutional Review Board.

The clinical data include admission year, Injury Severity Score (ISS), imaging studies, use of cervical collar immobilization, diagnosis of c-spine injury, surgical interventions, and deaths. Additional reports from Pediatrics, Ophthalmology, Neurosurgery, Intensive Care Unit, and Social Work Services were reviewed whenever necessary.

\section{Clinical Pathway Development}

In 2011, a multidisciplinary committee comprising representatives from Neurosurgery, Critical Care, Child Advocacy, Radiology, and General Surgery was assembled to develop a comprehensive clinical pathway regarding the care of patients with NAT. The portion of the pathway relevant to this study indicates brain MRI acquisition if the following conditions occur: 1) head CT scan confirms intracranial injury; 2) head CT scan is negative but the child has a decreased level of consciousness; or 3) clinical symptoms are not proportionate to head CT scan finding.

Importantly, whenever MRI of the brain was to be obtained, at the discretion of the physicians, MRI of the cspine was to be acquired concurrently regardless of clinical suspicion of c-spine injuries. The aim of this study was to assess the clinical impact of this portion of the clinical care pathway. The protocol was finalized and implemented in the spring of 2012.

\section{Statistical Analysis}

Descriptive statistics were presented as medians with interquartile range (IQR) for continuous variables, and frequency with percentage for categorical variables. The Mann-Whitney U-test and Fisher's exact test were used to determine any statistically significant differences in selected clinical values between the pre- and postclinical pathway groups. The significance level was set at $\alpha=0.05$, and IBM SPSS Statistics, Version 23 (IBM Corp.) was used for statistical analysis.

\section{Results}

\section{General Patient Characteristics and Findings}

Of the 503 patients, $56.7 \%(\mathrm{n}=285)$ were male. The median age at admission was 6 months. Most of the patients were infants $(<1$ year old, $71.2 \%)$ or toddlers $(1-3$ years old, 18.7\%). An ISS of $\geq 16(\mathrm{n}=219,43.5 \%)$ was defined as severe injury. Head injuries, including skull fracture without intracranial injury, were present in 343 cases $(68.2 \%)$. There were 51 deaths. The demographic and clinical characteristics of the patients are summarized in Table 1.

A total of 91 patients (18.1\%) underwent cMRI during the study periods. The majority $(98.9 \%)$ were younger than 36 months of age. Indications for obtaining the cMRI were documented as part of the NAT workup in most cases, but in 8 cases the cMRI was obtained because of clinical suspicion for c-spine injury. The indications for obtaining cMRI in these 8 cases were prevertebral swelling $(\mathrm{n}=$ $1)$, hemiparesis $(n=2)$, irregular spacing between spinous processes on radiographs $(n=3), C 2 / 3$ subluxation $(n=1)$, and $\mathrm{C} 5 / 6$ distraction injury $(\mathrm{n}=1)$.

Sixty-three of the 91 cMRI findings identified no injury (69.2\%). Forty-one c-spine abnormalities were identified in 28/91 (30.8\%) cMRI studies: spinal cord injuries $(\mathrm{n}=$ $4)$, soft-tissue injuries $(n=22)$, ligamentous injuries $(n=$ 13), and subdural bleeding $(n=2)$. The total number of c-spine abnormalities exceeded the number of positive MRIs because multiple findings were possible within a single study.

The patients with spinal cord injuries $(n=4)$ presented with the following clinical signs and symptoms: loss of spontaneous movement in the extremities, lack of response to painful stimulation to the extremities, and difficulty breathing. Table 2 summarizes these 4 patients with spinal cord injuries secondary to NAT. Of note, among 4 patients with spinal cord injury secondary to NAT, 3 had head injury but the remaining patient had normal results on head CT and brain MRI. This suggests that c-spine injury in this patient population may occur in the absence of intracranial injury.

A total of 128 surgical interventions were performed in 107 patients. Forty-seven of these patients underwent 66 neurosurgical operations and procedures. These included decompressive craniectomy $(\mathrm{n}=12)$, craniotomy for evacuation of hematoma $(\mathrm{n}=11)$, bur hole evacuation of subdural hematomas (SDHs) $(n=5)$, insertion of external ventricular drain $(n=10)$, placement of intracranial pressure monitor $(\mathrm{n}=14)$, placement of subdural peritoneal shunt $(n=8)$, ventriculoperitoneal shunt $(n=1)$, ventriculostomy $(n=1)$, and repair of skull fractures $(n=3)$. There was only 1 case of posterior c-spine fusion. This patient had a C5/6 distraction injury identified on the c-spine CT prior to cMRI examination. Most of the 62 nonneurosurgical operations were reduction and fixation of fractures (n =37). The other 25 nonneurosurgical operations included exploratory laparotomy, repair of intestinal injury, tracheotomy, bronchoscopy, and laryngoscopy.

\section{Cervical Collars and cMRI Findings}

Cervical hard collars were applied by the Emergency 
TABLE 1. Clinical characteristics of 503 pediatric patients with NAT

\begin{tabular}{|c|c|c|c|c|}
\hline \multirow[b]{2}{*}{ Variable } & \multirow[b]{2}{*}{$\begin{array}{l}\text { All Pts, } \\
n=503\end{array}$} & \multicolumn{2}{|c|}{ Comparison } & \multirow[b]{2}{*}{$\begin{array}{c}p \\
\text { Value }\end{array}$} \\
\hline & & $\begin{array}{l}\text { Preclinical Pathway, } \\
\qquad n=249\end{array}$ & $\begin{array}{l}\text { Postclinical Pathway, } \\
\qquad n=254\end{array}$ & \\
\hline Median age on admission, in mos [IQR] & $6[2-15]$ & $6[3-21]$ & $5[2-11]$ & 0.068 \\
\hline$<12$ & $358(71.2)$ & $164(65.9)$ & $194(76.4)$ & \\
\hline $12-35$ & $94(18.7)$ & $53(21.3)$ & $41(16.1)$ & \\
\hline$\geq 36$ & $51(10.1)$ & $32(12.9)$ & $19(7.5)$ & \\
\hline \multicolumn{5}{|l|}{ Sex } \\
\hline Female & $218(43.3)$ & $108(43.4)$ & $110(43.3)$ & 1.000 \\
\hline Male & $285(56.7)$ & $141(56.6)$ & $144(56.7)$ & \\
\hline Median ISS on admission [IQR] & $10[5-18]$ & $10[5-18]$ & $10[5-20]$ & 0.643 \\
\hline$\geq 16$ : severe injury & $219(43.5)$ & $109(43.8)$ & $110(43.3)$ & 0.929 \\
\hline$<16$ & $284(56.5)$ & $140(56.2)$ & $144(56.7)$ & \\
\hline Median GCS score on admission in 498 pts [IQR] & $15[14-15]$ & $15[8-15]$ & $15[15-15]$ & 0.127 \\
\hline 3-8: severe brain injury & $110 / 498(22.1)$ & $63 / 245(25.7)$ & $47 / 253(18.6)$ & 0.066 \\
\hline 9-12: moderate brain injury & $11 / 498(2.2)$ & $5 / 245(2.0)$ & $6 / 253(2.4)$ & \\
\hline 13-15: mild brain injury & $377 / 498(75.7)$ & $177 / 245(72.2)$ & $200 / 253(79.1)$ & \\
\hline Presence of head injury & $343(68.2)$ & $173(69.5)$ & $170(66.9)$ & 0.566 \\
\hline Skull fracture only & $49 / 343(14.3)$ & $24 / 173(13.9)$ & $25 / 170(14.7)$ & \\
\hline Skull fracture w/ intracranial injuries & $76 / 343(22.2)$ & $39 / 173(22.5)$ & $37 / 170(21.8)$ & \\
\hline Intracranial injuries w/o skull fractures & $218 / 343(63.6)$ & $110 / 173(63.6)$ & $108 / 170(63.5)$ & \\
\hline Pts w/ cMRI & $91(18.1)$ & $7(2.8)$ & $84(33.1)$ & $<0.0001$ \\
\hline cMRI+ & 28/91 (30.8) & $2 / 7(28.6)$ & $26 / 84(31.0)$ & 1.000 \\
\hline cMRI- & $63 / 91(69.2)$ & $5 / 7(71.4)$ & $58 / 84(69.1)$ & \\
\hline Incidence of c-spine injury & $28(5.6)$ & $2(0.8)$ & $26(10.2)$ & $<0.0001$ \\
\hline Pts w/ c-collar & $111(22.1)$ & $41(16.5)$ & $70(27.6)$ & 0.004 \\
\hline Discharged w/ c-collar & $8 / 111(7.2)$ & $0 / 41(0.0)$ & $8 / 70(11.4)$ & 0.025 \\
\hline Died before c-collar clearance & 22/111 (19.8) & $11 / 41(26.8)$ & $11 / 70(15.7)$ & 0.217 \\
\hline Pts w/ surgical treatment & $107(21.3)$ & $51(20.5)$ & $56(22.1)$ & 0.744 \\
\hline Craniotomy/craniectomy & $22(4.4)$ & $13(5.2)$ & $9(3.5)$ & 0.390 \\
\hline C-spine stabilization & $1(0.4)$ & $0(0.0)$ & $1(0.4)$ & \\
\hline Mortality & $51(10.1)$ & $32(12.9)$ & $19(7.5)$ & 0.055 \\
\hline
\end{tabular}

C-collar = cervical collar; GCS = Glasgow Coma Scale; pts = patients; + = positive findings; - = negative findings .

Boldface type indicates statistical significance. Except where otherwise specified, values are expressed as the number of patients (\%).

Medical Service or the Emergency Department physician to 111 of the 503 patients (22.1\%). Of those, $36.9 \%$ (41/111) underwent cMRI investigation. Notably, 22 of these 111 patients (19.8\%) died during hospitalization before the cervical collars were removed. For the remaining patients, c-spine examination and clearance was performed by either General Surgery or Neurosurgery services. Eight patients were discharged with cervical collar immobilization and were followed by a neurosurgeon. All 8 patients who were discharged with a cervical collar were given a follow-up appointment with a neurosurgeon. One patient was lost to follow-up, and the other 7 were cleared by clinical examination only $(n=4)$ or with additional neck radiographs $(\mathrm{n}=3)$.

The decision to keep patients in a cervical collar was made by individual neurosurgeons. Cervical spine abnormalities found in patients who were kept in cervical collars were as follows: increased fluid signal in the atlantoaxial
TABLE 2. Patients with spinal cord injury secondary to NAT

\begin{tabular}{ccclc}
\hline $\begin{array}{c}\text { Case } \\
\text { No. }\end{array}$ & $\begin{array}{c}\text { Adme on } \\
\text { (mos) }\end{array}$ & C-Spine Injury & Associated Injuries & ISS \\
\hline 1 & 18 & $\begin{array}{c}\text { Ischemic injury w/in } \\
\text { central portion of } \\
\text { upper cervical cord }\end{array}$ & SAH & 25 \\
\hline 2 & $<1$ & C5/6 distraction injury & Clavicle fracture & 29 \\
\hline 3 & 2 & Cervical cord edema & $\begin{array}{c}\text { Skull fracture, SAH, } \\
\text { SDH, EDH }\end{array}$ & 25 \\
\hline 4 & 29 & Cervical cord edema & $\begin{array}{c}\text { Skull fracture, } \\
\text { intraparenchymal } \\
\text { hematoma, SDH }\end{array}$ & 25 \\
\hline & & & & \\
\hline
\end{tabular}

$\mathrm{EDH}=$ epidural hematoma; $\mathrm{SAH}=$ subarachnoid hemorrhage. 
and occipital articulations, abnormal fluid signal within the posterior supraspinal soft tissues on the course of the nuchal ligament, abnormal long-segment T2-weighted hyperintensity along the dorsal epidural soft tissues, focal defect in the ligamentum flavum at C1-2 with focal ligamentous injury, abnormal signal between the posterior arch of C-1 and C-2 with interspinous ligament injury, retropharyngeal edema in the upper cervical spine to the level of $\mathrm{C}-4$, subacute blood products identified in the lower cervical to midthoracic spine measuring $4 \mathrm{~mm}$ in thickness, SDH along the posterior margin of the dens measuring $1 \mathrm{~mm}$ in thickness. Even though the criteria for rigid collar usage were not explicitly stated in the charts in most cases, it appears that the neurosurgical service applied the collar whenever suspected ligamentous, joint capsule, or intraspinal injuries were involved, whereas soft-tissue injuries (i.e., generalized edema within muscle) did not prompt the same course of action.

\section{Correlations Among cMRI, Radiographic, and CT Findings}

Among the 503 patients, 95 underwent c-spine radiography or CT and 91 underwent cMRI. Approximately onethird of the patients with cMRI had prior radiography and/ or CT imaging of the cervical spine. Of 28 patients with abnormal (i.e., positive) cMRI results, 11 had prior c-spine radiography and/or CT, with 2 abnormal and 9 normal findings. Cervical spine abnormalities in 9 patients with positive cMRI findings but negative prior c-spine radiographs or CT scans were all soft-tissue and ligamentous injuries, as expected, and no surgical intervention was needed. Of 2 patients with positive findings on cMRI and radiography and/or CT imaging, osseous changes were noted.

Next, we asked if having abnormal findings on c-spine CT or cervical radiography was more likely to raise the pretest probability of identifying an injury on cMRI. Of the 95 patients who underwent c-spine radiography and/or CT, 75 had normal results. We found no significant difference in the cMRI-positive rate between those with positive readings in prior $\mathrm{c}$-spine $\mathrm{CT}$ and/or radiographs and those with negative ones ( $40.0 \%$ vs $39.1 \%$ ). In summary, CT and/ or radiography and cMRI seemed to detect such nonoverlapping pathological processes that one does not serve as a screening test for the other.

\section{Comparing Pre- and Postclinical Pathway Implementation Groups}

There was no difference in sex, ISS, or incidence of head injury between the pre- and postclinical pathway groups (Table 1). There were no statistically significant changes in the number of cranial procedures (preclinical $5.2 \%$ vs postclinical $3.5 \% ; p=0.39$ ). Only 1 case of $c-$ spine surgical stabilization (posterior cervical fusion) occurred in 2012.

Yearly changes in the number of patients with NAT, head injury, and cMRI are depicted in Fig. 1. Significantly more patients underwent cMRI after pathway implementation (33.1\% vs $2.8 \%, \mathrm{p}<0.0001)$. Compared with patients in the group treated before clinical pathway implementation, those in the group treated after clinical pathway implementation were more likely to have cervical collars placed $(16.5 \%$ vs $27.6 \% ; \mathrm{p}=0.004)$. Whereas no patients were discharged with cervical collar immobilization before the pathway implementation, 8 patients in the postpathway period were discharged with a cervical collar. There were no differences between the 2 groups in the proportion of patients who died before cervical collar clearance (preclearance $26.8 \%$ [11/41] vs postclearance $15.7 \%[11 / 70] ; \mathrm{p}=0.217)$. There was a decrease in deaths from $12.9 \%$ to $7.5 \%$ between the 2 periods.

\section{Discussion}

\section{Incidence of c-Spine Injury in Patients With NAT}

Pediatric spine injuries are relatively infrequent in the setting of trauma, with an overall reported incidence of $1 \%-3 \%,{ }^{18,24,29,30}$ and child abuse represents an important cause of those injuries. In 1 study, Knox et al. reported 8 c-spine injuries, including osseous, ligamentous, and spinal cord injury types, among 726 cases of NAT (1.0\%).22 These 8 patients were identified by clinical symptoms and recorded in a database of 342 children diagnosed with spine injuries between 2003 and 2011. The authors then applied the number to a total of 726 patients with NAT during the study period to calculate the incidence of cspine trauma induced by NAT. Kadom et al..$^{19}$ took a somewhat different approach; close to half of their patients with NAT (74 of 161) underwent a cMRI study. Even though the indication for obtaining cMRI was not described, one can probably assume that most of their patients had no signs and symptoms suggesting c-spine injury. Not surprisingly, when cMRI was used in this manner, more injuries were identified; $16.8 \%$ (27/161) of children with suspected abusive head trauma harbored concurrent c-spine injuries.

These 2 representative studies demonstrate the difficulty in determining the true incidence of c-spine injury in the population of patients with NAT. Differences in age cutoffs in the studies, the diagnostic methods of choice and the indications for obtaining the study, and the definition of injury (radiographic vs clinical) could all potentially affect the reported incidence. In our study, we report an incidence of 5.6\% (28/503) for c-spine injuries in children with NAT, which is within the range reported in the current literature. It needs to be pointed out that this reflects a single institution's current practice, and might not reflect the true incidence of such injuries.

\section{Detecting c-Spine Injuries in the NAT Population}

Although routine cMRI can provide more insight into the incidence of c-spine injuries in NAT, it remains to be seen whether routine imaging results in improved clinical outcomes and patient management. When the cMRI yields negative results, the high negative predictive value of such a finding enables clinicians to clear the cervical spine even in obtunded and intubated pediatric patients. ${ }^{11,12,20}$ This is not trivial because the clinical scenario is not uncommon; however, the cost-effectiveness is open to question. Como et al. ${ }^{6}$ and Tomycz et al. ${ }^{32}$ concluded that MRI was unlikely to reveal c-spine injury when CT was negative in obtunded trauma patients. Similarly, we found no significant difference in the cMRI-positive rate between those 


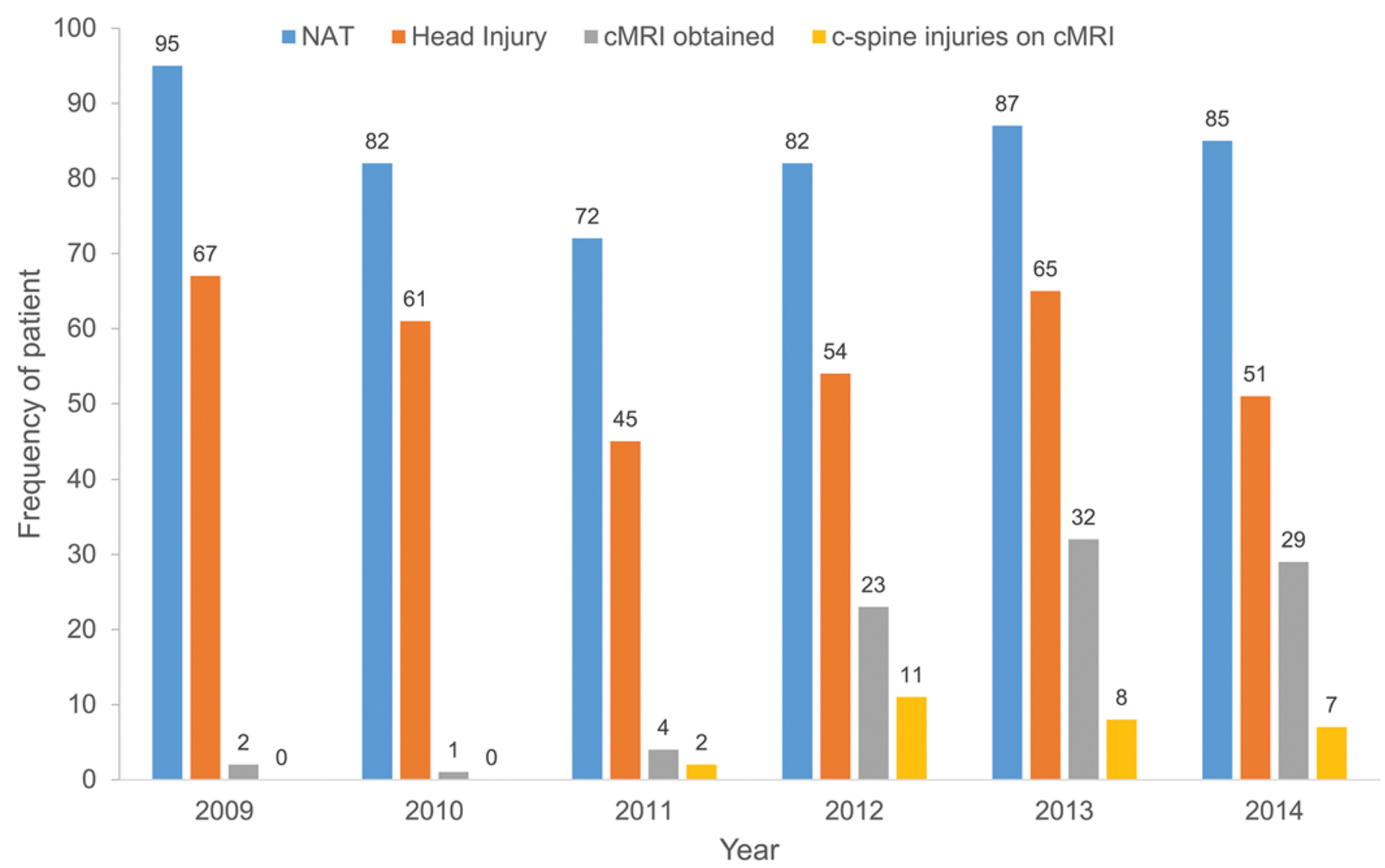

FIG. 1. Bar graph showing changes in patients with NAT, head injury, and cMRI by year. Figure is available in color online only.

with positive readings on prior c-spine CT scans and/or radiographs and those with negative ones (40.0\% vs $39.1 \%)$. A likely explanation is that $\mathrm{CT}$ and radiography are better at identifying osseous injuries and MRI at identifying soft-tissue injuries, and one type of injury can occur in the absence of the other.

Although soft-tissue and ligamentous injury were the most common findings from the cMRI screening, their clinical significance remains unknown. Several studies have reported MRI to give a high false-positive rate and demonstrated that CT scans are superior in distinguishing clinically significant c-spine injuries that require surgical interventions. ${ }^{1,3,16,26}$ Furthermore, in these studies, softtissue and ligamentous injuries were not always distinguished. Presumably, because of the findings of ligamentous injury on cMRI, a higher proportion of children were placed in cervical collars following discharge in the postpathway period. Whether this resulted in earlier detection or prevention of delayed instability ${ }^{7,14,28}$ cannot be fully determined by this study. In our 3 patients with clearly documented ligamentous injury, none had developed delayed instability after 18 months.

\section{Effects of Pathway Implementation in Our Institution}

We found that after the pathway was implemented, the rate of cMRI use increased dramatically (from $2.8 \%$ to $33.1 \%$ ). Even though more radiographic injuries were identified in the postpathway group, the positive yield rate of c-spine injuries from the MRI remained nearly the same (preclinical pathway, $28.6 \%$ vs postclinical pathway, $31.0 \%$ ). Frank et al., ${ }^{12}$ examining the effects of cMRI usage in children with trauma injuries after a protocol implementation, reported similar findings. In that study, the number of patients undergoing cMRI increased over time but the positive yield rate of cMRI did not. Even though intuitively we believe that the usage of cMRI is probably excessive, our current study does not provide enough statistical power to detect differences in the 2 groups when the event of interest is very rare.

The clinical pathway had a measurable effect of raising the awareness of potential c-spine injury in this patient group. This was most obvious when we detected an increase in cervical collar use at patients' initial presentations, from $16.5 \%$ to $27.6 \%$. However, it is important to point out that the clinical impact of this change in practice is hard to measure. The purpose of rigid collar immobilization is to minimize injury to the spinal cord and spinal column before a full clinical assessment can be obtained. Because iatrogenic injury to the cervical spine remains rare, some patients could potentially have benefited from this practice pattern change, but the number is likely to be small.

The main benefit that was realized in our institution was more standardized care. We did not expect or detect noticeable differences with clinical results. Currently the practice of cMRI acquisition in this patient group is driven mostly by the Child Protection Service team, which argues that information derived from cMRI is useful in de- 
ciphering the cause of injury. The results of this study will be used in future discussions of protocol modifications.

\section{Limitations of the Study}

First, the clinical pathway left the ultimate decision to obtain MRI studies to the treating physicians; therefore, not all patients with head injury underwent cMRI. It is possible that some patients harbor soft-tissue injury or even spinal cord injury that is not clinically detected. Second, the practice of $\mathrm{c}$-spine clearance varies greatly depending on which neurosurgeon is seeing the patient. For example, some will clear the cervical spine based on negative cMRI results even though the patient is still intubated, whereas some insist on clinical examination after extubations. Regardless of the criteria, the missed injury rates have been low. During our study period, there was no significant delay of diagnosis. Third, a retrospective chart review did not provide the information necessary to assess variations in physicians' decision making regarding cMRI acquisition. Last, the rarity of clinically significant spinal cord injury hampered statistical analysis. Cases of delayed instability are of immense interest, but the length of follow-up for the pre- and postpathway groups was not sufficient to determine its frequency fully.

\section{Conclusions}

Children are uniquely vulnerable to NAT, and their physiology predisposes them to cranial and c-spine injury. The development of a cMRI protocol had the effect of raising awareness of potential c-spine injury in this patient population and had a measurable impact on clinical practices and imaging use.

\section{References}

1. Anderson SE, Boesch C, Zimmermann H, Busato A, Hodler J, Bingisser R, et al: Are there cervical spine findings at MR imaging that are specific to acute symptomatic whiplash injury? A prospective controlled study with four experienced blinded readers. Radiology 262:567-575, 2012

2. Billmire ME, Myers PA: Serious head injury in infants: accident or abuse? Pediatrics 75:340-342, 1985

3. Brockmeyer DL, Ragel BT, Kestle JR: The pediatric cervical spine instability study. A pilot study assessing the prognostic value of four imaging modalities in clearing the cervical spine for children with severe traumatic injuries. Childs Nerv Syst 28:699-705, 2012

4. Brown RL, Brunn MA, Garcia VF: Cervical spine injuries in children: a review of 103 patients treated consecutively at a level 1 pediatric trauma center. J Pediatr Surg 36:11071114,2001

5. Choudhary AK, Ishak R, Zacharia TT, Dias MS: Imaging of spinal injury in abusive head trauma: a retrospective study. Pediatr Radiol 44:1130-1140, 2014

6. Como JJ, Thompson MA, Anderson JS, Shah RR, Claridge JA, Yowler CJ, et al: Is magnetic resonance imaging essential in clearing the cervical spine in obtunded patients with blunt trauma? J Trauma 63:544-549, 2007

7. Davis JW, Phreaner DL, Hoyt DB, Mackersie RC: The etiology of missed cervical spine injuries. J Trauma 34:342-346, 1993

8. Duhaime AC, Alario AJ, Lewander WJ, Schut L, Sutton LN, Seidl TS, et al: Head injury in very young children: mechanisms, injury types, and ophthalmologic findings in 100 hospitalized patients younger than 2 years of age. Pediatrics 90:179-185, 1992

9. Ewing-Cobbs L, Prasad M, Kramer L, Louis PT, Baumgartner J, Fletcher JM, et al: Acute neuroradiologic findings in young children with inflicted or noninflicted traumatic brain injury. Childs Nerv Syst 16:25-34, 2000

10. Feldman KW, Bethel R, Shugerman RP, Grossman DC, Grady MS, Ellenbogen RG: The cause of infant and toddler subdural hemorrhage: a prospective study. Pediatrics 108:636-646, 2001

11. Flynn JM, Closkey RF, Mahboubi S, Dormans JP: Role of magnetic resonance imaging in the assessment of pediatric cervical spine injuries. J Pediatr Orthop 22:573-577, 2002

12. Frank JB, Lim CK, Flynn JM, Dormans JP: The efficacy of magnetic resonance imaging in pediatric cervical spine clearance. Spine (Phila Pa 1976) 27:1176-1179, 2002

13. Geddes JF, Hackshaw AK, Vowles GH, Nickols CD, Whitwell HL: Neuropathology of inflicted head injury in children. I. Patterns of brain damage. Brain 124:1290-1298, 2001

14. Gerrelts BD, Petersen EU, Mabry J, Petersen SR: Delayed diagnosis of cervical spine injuries. J Trauma 31:1622-1626, 1991

15. Ghatan S, Ellenbogen RG: Pediatric spine and spinal cord injury after inflicted trauma. Neurosurg Clin N Am 13:227233, 2002

16. Goradia D, Linnau KF, Cohen WA, Mirza S, Hallam DK, Blackmore CC: Correlation of MR imaging findings with intraoperative findings after cervical spine trauma. AJNR Am J Neuroradiol 28:209-215, 2007

17. Herman BE, Makoroff KL, Corneli HM: Abusive head trauma. Pediatr Emerg Care 27:65-69, 2011

18. Hernandez JA, Chupik C, Swischuk LE: Cervical spine trauma in children under 5 years: productivity of CT. Emerg Radiol 10:176-178, 2004

19. Kadom N, Khademian Z, Vezina G, Shalaby-Rana E, Rice A, Hinds T: Usefulness of MRI detection of cervical spine and brain injuries in the evaluation of abusive head trauma. Pediatr Radiol 44:839-848, 2014

20. Keiper MD, Zimmerman RA, Bilaniuk LT: MRI in the assessment of the supportive soft tissues of the cervical spine in acute trauma in children. Neuroradiology 40:359-363, 1998

21. Kemp AM, Joshi AH, Mann M, Tempest V, Liu A, Holden $\mathrm{S}$, et al: What are the clinical and radiological characteristics of spinal injuries from physical abuse: a systematic review. Arch Dis Child 95:355-360, 2010

22. Knox J, Schneider J, Wimberly RL, Riccio AI: Characteristics of spinal injuries secondary to nonaccidental trauma. J Pediatr Orthop 34:376-381, 2014

23. Knox JB, Schneider JE, Cage JM, Wimberly RL, Riccio AI: Spine trauma in very young children: a retrospective study of 206 patients presenting to a level 1 pediatric trauma center. J Pediatr Orthop 34:698-702, 2014

24. Kokoska ER, Keller MS, Rallo MC, Weber TR: Characteristics of pediatric cervical spine injuries. J Pediatr Surg 36:100-105, 2001

25. Leventhal JM, Gaither JR: Incidence of serious injuries due to physical abuse in the United States: 1997 to 2009. Pediatrics 130:e847-e852, 2012

26. Pieretti-Vanmarcke R, Velmahos GC, Nance ML, Islam S, Falcone RA Jr, Wales PW, et al: Clinical clearance of the cervical spine in blunt trauma patients younger than 3 years: a multi-center study of the American Association for the Surgery of Trauma. J Trauma 67:543-550, 2009

27. Piteau SJ, Ward MG, Barrowman NJ, Plint AC: Clinical and radiographic characteristics associated with abusive and nonabusive head trauma: a systematic review. Pediatrics 130:315-323, 2012

28. Platzer P, Hauswirth N, Jaindl M, Chatwani S, Vecsei V, Gaebler C: Delayed or missed diagnosis of cervical spine injuries. J Trauma 61:150-155, 2006 
29. Platzer P, Jaindl M, Thalhammer G, Dittrich S, Kutscha-Lissberg F, Vecsei V, et al: Cervical spine injuries in pediatric patients. J Trauma 62:389-396, 2007

30. Polk-Williams A, Carr BG, Blinman TA, Masiakos PT, Wiebe DJ, Nance ML: Cervical spine injury in young children: a National Trauma Data Bank review. J Pediatr Surg 43:1718-1721, 2008

31. Ryan ME, Palasis S, Saigal G, Singer AD, Karmazyn B, Dempsey ME, et al: ACR appropriateness criteria head trauma-child. J Am Coll Radiol 11:939-947, 2014

32. Tomycz ND, Chew BG, Chang YF, Darby JM, Gunn SR, Nicholas DH, et al: MRI is unnecessary to clear the cervical spine in obtunded/comatose trauma patients: the four-year experience of a level I trauma center. J Trauma 64:12581263,2008

33. U.S. Department of Health and Human Services: Child Maltreatment 2013. Washington, DC: US Department of Health and Human Services, Administration for Children and Families, 2015 (http://www.acf.hhs.gov/programs/ $\mathrm{cb} /$ research-data-technology/statistics-research/childmaltreatment) [Accessed May 1, 2017]

\section{Disclosures}

The authors report no conflict of interest concerning the materials or methods used in this study or the findings specified in this paper.

\section{Author Contributions}

Conception and design: Chern, Oh. Acquisition of data: Oh. Analysis and interpretation of data: Oh. Drafting the article: Oh. Critically revising the article: all authors. Reviewed submitted version of manuscript: all authors. Approved the final version of the manuscript on behalf of all authors: Chern. Statistical analysis: Oh.

\section{Correspondence}

Joshua J. Chern, Children's Healthcare of Atlanta, 5455 Meridian Mark Rd. NE, Ste. 540, Atlanta, GA 30342. email: joshua.chern@ choa.org. 